\title{
Genetic Distances in Three Ascidian Species determined by PCR Technique
}

\author{
${ }^{\dagger}$ Jong-Man Yoon \\ Dept. of Aquatic Life Medicine, College of Ocean Science and Technology, \\ Kunsan National University, Gunsan 54150, Korea
}

\begin{abstract}
Seven oligonucleotides primers were shown to generate the shared loci, specific loci, unique shared loci to each species and shared loci by the three species which could be obviously scored. In the present study, 7 oligonucleotides primers produced 401 total loci in the Styela clava (SC) species, 390 in the Halocynthia roretzi (HR) and 434 in the Styela plicata (SP), respectively. Seven oligonucleotides primers generated 275 specific loci in the SC, 341 in the HR and 364 in the SP species, respectively. The oligonucleotides primer BION-23 generated 28 unique loci to each species in the SP species. Especially, the oligonucleotides primer BION-25 produced 7 unique loci to each species, which were identifying each species in the SP species. BION-17 distinguished 21 shared loci by the three ascidian species, major and/or minor fragments of sizes, which were identical in almost all of the samples. Based on the average bandsharing values of all samples, the similarity matrix ranged from 0.519 to 0.774 in the SC species, from 0.261 to 0.683 in the HR species and from 0.346 to 0.730 in the SP species. As regards average bandsharing value (BS) results, individuals from SC species $(0.661 \pm 0.081)$ exhibited higher bandsharing values than did individuals from HR species $(0.555 \pm 0.074)(P<0.05)$. The dendrogram obtained by the seven oligonucleotides primers indicates three genetic groups. In three ascidian species, the shortest genetic distance (0.071) exhibiting significant molecular difference was also between individual no. 20 and no. 21 within the SP species.
\end{abstract}

Key words : Genetic distance, Halocynthia roretzi, Hierarchical dendrogram, Similarity matrix, Styela clava, Styela plicata

\section{INTRODUCTION}

In the present study, three ascidian species such as Styela clava (SC), Halocynthia roretzi $(\mathrm{HR})$ and Styela plicata (SP), belonging to the class Ascidiacea, are the most popular marine products in Korea because of their scent, flavor and nourishing value, and Koreans consume them plentifully. These ascidians, economically important marine species broadly distributed on the coast of southern sea of the Korean peninsula and the several sea areas in the natural ecosystem. However, notwithstanding their economic and scientific significances, a little information currently exists concerning the stability of producibility (Huh \& Choi, 2008), the physiology (Shin et al., 2007) and the development of aquacultural technique (Lee, 2011) points only of ascidian species in Korea. Also, during the last two decades, parasite outbreak and various environmental disruptions by industries, city sewage and global warming, have threatened the coastal fisheries, and then reduction of individual number of this invertebrate is an increasing trend in the 2000s. Among various PCR-based molecular techniques, RAPDs are the most frequently used molecular markers for

\footnotetext{
Manuscript received October 27, 2016, Received in revised form November 19, 2016, Accepted December 21, 2016

${ }^{\dagger}$ Corresponding Author : Jong-Man Yoon, Dept. of Aquatic Life Medicine, College of Ocean Science and Technology, Kunsan National University, Gunsan 54150, Korea. Tel. : +82-63-469-1887, E-mail : jmyoon@kunsan.ac.kr

This is an Open Access article distributed under the terms of the Creative Commons Attribution Non-Commercial License (http:// creativecommons.org/licenses/by-nc/3.0) which permits unrestricted non-commercial use, distribution, and reproduction in any medium, provided the original work is properly cited.
} 
taxonomic and systematic analyses of organisms (Adams, 2000; Bartish et al., 2000). Particularly, the polymorphic and/or specific markers specific to the breed, the species, the genus or the geographical population have been applied for the identification of individuals and population, hybrid parentage and for the screening of DNA (Guo et al., 2001). Generally, RAPD-PCR is one of fast and simple research methods to identify genetic difference and the polymorphism in various organisms that does not require the prior knowledge of the genomic DNA (Iyengar et al., 2000; Nebauer et al., 2000; Nicolosi et al., 2000). In this study, to explicate the genetic distances among ascidian species, the author achieved a clustering analysis of three ascidian species collected from the southern sea.

\section{MATERIALS AND METHODS}

Muscle tissues were obtained separately from individuals of three ascidian species such as Styela clava (SC), Halocynthia roretzi (HR) and Styela plicata (SP) from the southern sea of the Korean Peninsula, respectively. The muscle was collected in sterile tubes, immediately placed on dry ice, and stored at under freezing until the genomic DNA extraction. Genomic DNA was extracted and purified under the conditions designated previously (Yoon \& Kim, 2004; Song \& Yoon, 2013). The DNA pellets were incubationdried for $2 \mathrm{hrs}$, held at $-40^{\circ} \mathrm{C}$ until analysis, and then dissolved in the TE buffer $(10 \mathrm{mM}$ Tris- $\mathrm{HCl}, \mathrm{pH} 8.0 ; 1$ mM EDTA). The concentrations of the extracted genomic DNA samples were estimated based on the absorbance at 260 $\mathrm{nm}$ by a spectrophotometer (Beckman Coulter, Buckinghamshire, UK). PCR analysis was accomplished on DNA samples extracted from a total of 21 individuals using seven oligonucleotides primers. Seven oligonucleotides primers BION-11 (5'-GTGATCGCAG-3'), BION-13 (5'-GTTTCG CTCC-3'), BION-17 (5'-TGCTCTGCCC-3'), BION-21 (5'AATCGGGCTG-3'), BION-23 (5'-CAGGCGGCGT-3'), BION25 (5'-CTGGCGGCTG-3') BION-30 (5'-GCCACCTCCT-
3') were demonstrated to produce the total loci, average loci per lane, specific loci, unique loci to each species and shared loci by the three species which could be clearly counted. The degree of variability was estimated by use of the Dice coefficient $(F)$, which is given by the formula: $F$ $=2 \mathrm{nab} /(\mathrm{na}+\mathrm{nb})$, where nab is the number of bands shared between the samples $a$ and $b$, na is the total number of bands for sample a and $\mathrm{nb}$ is the total number of bands for sample b (Jeffreys \& Morton, 1987; Yoke-Kqueen \& Radu, 2006). Euclidean genetic distances within- and betweenspecies were also calculated by complete linkage method with the support of the hierarchical dendrogram program Systat version 13 (SPSS Inc., Chicago, IL, USA).

\section{RESULTS AND DISCUSSION}

The genomic DNA isolated from three ascidians such as Styela clava (SC), Halocynthia roretzi (HR) and Styela plicata (SP) in the southern sea, respectively, were amplified several times by PCR reaction (unpublished data). Similarity matrix including bandsharing values (BS) was calculated using Nei and Li's index of the similarity of ascidian individuals from the southern sea of the Korean Peninsula, respectively, as demonstrated in Table 1. Based on the average bandsharing values of all samples, the similarity matrix ranged from 0.519 to 0.774 in the SC species, from 0.261 to 0.683 in the HR species and from 0.346 to 0.730 in the SP species, as illustrated in Table 1. The bandsharing value between individuals no. 01 and no. 02 was 0.774 , which was the highest value identified within the SC species. Seven oligonucleotides primers were shown to generate the shared loci, specific loci, which could be obviously scored, as demonstrated in Table 2. In the present study, 7 oligonucleotides primers produced 401 total loci in the SC, 390 in the HR and 434 in the SP species, respectively. Also, these oligonucleotides primers produced 275 specific loci in the SC, 341 in the HR and 364 in the SP species, respectively. The specific loci generated by oligonucleotides 
Table 1. Similarity matrix including bandsharing values (BS) calculated using Nei and Li's index of the similarity of Styela clava (SC), Halocynthia roretzi (HR) and Styela plicata (SP) from the southern sea of the Korean Peninsula, respectively

\begin{tabular}{|c|c|c|c|c|c|c|c|c|c|c|c|c|c|c|c|c|c|c|c|c|c|}
\hline \multicolumn{22}{|c|}{ Bandsharing values of three species of Ascidiacea } \\
\hline \multicolumn{7}{|c|}{ from $S$. clava } & \multicolumn{7}{|c|}{ from $H$. roretzi } & \multicolumn{8}{|c|}{ from $S$. plicata } \\
\hline 1 & 2 & 3 & 4 & 5 & 6 & 7 & 8 & 9 & 10 & 11 & 12 & 13 & 14 & 15 & 16 & 17 & 18 & 19 & 20 & 21 & \\
\hline \multirow[t]{21}{*}{-} & 0.774 & 0.748 & 0.739 & 0.706 & 0.604 & 0.562 & 0.545 & 0.436 & 0.468 & 0.511 & 0.562 & 0.551 & 0.506 & 0.469 & 0.401 & 0.442 & 0.545 & 0.579 & 0.549 & 0.538 & 1 \\
\hline & - & 0.673 & 0.739 & 0.736 & 0.604 & 0.519 & 0.532 & 0.489 & 0.436 & 0.581 & 0.504 & 0.485 & 0.554 & 0.462 & 0.386 & 0.440 & 0.521 & 0.510 & 0.554 & 0.567 & 2 \\
\hline & & - & 0.703 & 0.749 & 0.642 & 0.578 & 0.540 & 0.427 & 0.353 & 0.545 & 0.416 & 0.457 & 0.575 & 0.484 & 0.453 & 0.346 & 0.556 & 0.589 & 0.597 & 0.575 & 3 \\
\hline & & & - & 0.772 & 0.601 & 0.563 & 0.489 & 0.376 & 0.390 & 0.468 & 0.503 & 0.441 & 0.440 & 0.554 & 0.494 & 0.496 & 0.606 & 0.577 & 0.581 & 0.622 & 4 \\
\hline & & & & - & 0.627 & 0.557 & 0.514 & 0.477 & 0.428 & 0.475 & 0.506 & 0.494 & 0.542 & 0.499 & 0.446 & 0.583 & 0.572 & 0.546 & 0.571 & 0.618 & 5 \\
\hline & & & & & - & 0.692 & 0.440 & 0.349 & 0.283 & 0.432 & 0.396 & 0.379 & 0.440 & 0.406 & 0.360 & 0.354 & 0.473 & 0.589 & 0.525 & 0.521 & 6 \\
\hline & & & & & & - & 0.423 & 0.379 & 0.261 & 0.445 & 0.413 & 0.411 & 0.407 & 0.410 & 0.448 & 0.437 & 0.497 & 0.551 & 0.503 & 0.470 & 7 \\
\hline & & & & & & & - & 0.565 & 0.539 & 0.496 & 0.554 & 0.543 & 0.448 & 0.429 & 0.408 & 0.453 & 0.503 & 0.548 & 0.524 & 0.503 & 8 \\
\hline & & & & & & & & - & 0.671 & 0.597 & 0.534 & 0.490 & 0.526 & 0.474 & 0.532 & 0.490 & 0.509 & 0.512 & 0.548 & 0.541 & 9 \\
\hline & & & & & & & & & - & 0.532 & 0.514 & 0.474 & 0.447 & 0.441 & 0.475 & 0.459 & 0.466 & 0.407 & 0.483 & 0.513 & 10 \\
\hline & & & & & & & & & & - & 0.683 & 0.552 & 0.665 & 0.475 & 0.438 & 0.415 & 0.535 & 0.490 & 0.526 & 0.473 & 11 \\
\hline & & & & & & & & & & & - & 0.641 & 0.510 & 0.492 & 0.500 & 0.398 & 0.503 & 0.501 & 0.546 & 0.509 & 12 \\
\hline & & & & & & & & & & & & - & 0.677 & 0.499 & 0.535 & 0.511 & 0.536 & 0.520 & 0.560 & 0.480 & 13 \\
\hline & & & & & & & & & & & & & - & 0.514 & 0.458 & 0.450 & 0.560 & 0.483 & 0.579 & 0.562 & 14 \\
\hline & & & & & & & & & & & & & & - & 0.693 & 0.575 & 0.554 & 0.504 & 0.484 & 0.512 & 15 \\
\hline & & & & & & & & & & & & & & & - & 0.623 & 0.580 & 0.586 & 0.558 & 0.585 & 16 \\
\hline & & & & & & & & & & & & & & & & - & 0.546 & 0.524 & 0.559 & 0.479 & 17 \\
\hline & & & & & & & & & & & & & & & & & - & 0.643 & 0.644 & 0.663 & 18 \\
\hline & & & & & & & & & & & & & & & & & & - & 0.659 & 0.632 & 19 \\
\hline & & & & & & & & & & & & & & & & & & & - & 0.730 & 20 \\
\hline & & & & & & & & & & & & & & & & & & & & - & 21 \\
\hline
\end{tabular}

Bandsharing values of three ascidian species are above the diagonal primers exhibited inter-species-specific characteristics, thus revealing DNA polymorphisms. Here, the seven oligo-nucleotides primers were used to generate the unique loci to each species and shared loci by the three species, as illustrated in Table 3. 126 unique shared loci to each species, with an average of 18 per primer, were observed in the SC species, 49 loci, with an average of 7 per primer, were observed in the HR species, and 70 loci, with an average of 10 per primer, and were observed in the SP species. The oligonucleotides primer BION-17 generated 28 unique loci to each species in the SC species. The oligonucleotides primer BION-23 generated 28 unique loci to each species in the SP species. Specifically, the oligonucleotides primer BION-13 generated 7 unique loci to each species, which were identifying each species in the HR species. Especially, the oligonucleotides primer BION25 generated 7 unique loci to each species, which were identifying each species in the SP species. Interestingly, BION-17 distinguished 21 shared loci by the three ascidian species, major and/or minor fragments of sizes, which were identical in almost all of the samples. Also, the primer BION-23 detected 21 shared loci by the three species, various fragments of sizes, which were identical in almost all of the samples. As regards average bandsharing value (BS) results, individuals from SC species $(0.661 \pm 0.081)$ 
Table 2. The number of average loci per lane and specific loci by PCR research using 7 oligonucleotides primers in Styela clava (SC), Halocynthia roretzi (HR) and Styela plicata (SP) species

\begin{tabular}{|c|c|c|c|c|c|c|}
\hline \multirow{2}{*}{$\begin{array}{c}\text { Item } \\
\text { Primer }\end{array}$} & \multicolumn{3}{|c|}{ No. of average loci per lane } & \multicolumn{3}{|c|}{ No. of specific loci } \\
\hline & $\mathrm{SC}$ & HR & SP & $\mathrm{SC}$ & HR & SP \\
\hline BION-11 & $\begin{array}{l}9.43 \\
(66)\end{array}$ & $\begin{array}{c}10.29 \\
(72)\end{array}$ & $\begin{array}{c}10.43 \\
(73)\end{array}$ & 45 & 51 & 52 \\
\hline BION-13 & $\begin{array}{l}8.14 \\
(57)\end{array}$ & $\begin{array}{l}8.14 \\
(57)\end{array}$ & $\begin{array}{l}6.29 \\
(44)\end{array}$ & 36 & 50 & 44 \\
\hline BION-17 & $\begin{array}{l}9.57 \\
(67) \\
\end{array}$ & $\begin{array}{l}5.14 \\
(36)\end{array}$ & $\begin{array}{l}9.71 \\
(68)\end{array}$ & 39 & 29 & 61 \\
\hline BION-21 & $\begin{array}{l}5.29 \\
(37)\end{array}$ & $\begin{array}{l}9.86 \\
(69) \\
\end{array}$ & $\begin{array}{l}9.71 \\
(68)\end{array}$ & 23 & 69 & 61 \\
\hline BION-23 & $\begin{array}{c}10.74 \\
(75)\end{array}$ & $\begin{array}{l}7.14 \\
(50)\end{array}$ & $\begin{array}{c}10.43 \\
(73)\end{array}$ & 54 & 36 & 45 \\
\hline BION-25 & $\begin{array}{l}7.71 \\
(54)\end{array}$ & $\begin{array}{l}8.14 \\
(57)\end{array}$ & $\begin{array}{l}8.29 \\
(58)\end{array}$ & 40 & 57 & 51 \\
\hline BION-30 & $\begin{array}{l}6.43 \\
(45)\end{array}$ & $\begin{array}{c}7 \\
(49)\end{array}$ & $\begin{array}{l}7.14 \\
(50)\end{array}$ & 38 & 49 & 50 \\
\hline Total no. & $\begin{array}{l}57.29 \\
(401)\end{array}$ & $\begin{array}{l}55.71 \\
(390)\end{array}$ & $\begin{array}{c}62 \\
(434)\end{array}$ & 275 & 341 & 364 \\
\hline Average no. per primer & 57.29 & 55.71 & 62 & 39.29 & 48.71 & 52 \\
\hline
\end{tabular}

SC: Styela clava, HR: Halocynthia roretzi, SP: Styela plicata

Table 3. The number of unique loci to each species and number of shared loci by the three species generated by PCR research using 7 oligonucleotides primers in Styela clava (SC), Halocynthia roretzi (HR) and Styela plicata (SP) species, respectively

\begin{tabular}{|c|c|c|c|c|}
\hline \multirow{2}{*}{$\frac{\text { Item }}{\text { Primer } \backslash \text { Species }}$} & \multicolumn{3}{|c|}{ No. of unique loci to each species } & \multirow{2}{*}{$\begin{array}{l}\text { No. of shared loci by the three species } \\
\text { Three species ( } 7 \text { individuals per species) }\end{array}$} \\
\hline & $\mathrm{SC}$ & HR & SP & \\
\hline BION - 11 & 21 & 21 & 21 & 0 \\
\hline BION - 13 & 21 & 7 & 0 & 0 \\
\hline BION - 17 & 28 & 7 & 7 & 21 \\
\hline BION - 21 & 14 & 0 & 7 & 0 \\
\hline BION - 23 & 21 & 14 & 28 & 21 \\
\hline BION - 25 & 14 & 0 & 7 & 0 \\
\hline BION - 30 & 7 & 0 & 0 & 0 \\
\hline Total no. & 126 & 49 & 70 & 42 \\
\hline Average no. per primer & 18 & 7 & 10 & 6 \\
\hline
\end{tabular}

SC: Styela clava, HR: Halocynthia roretzi, SP: Styela plicata 
Table 4. Several assessments of average bandsharing values among in Styela clava (SC), Halocynthia roretzi (HR) and Styela plicata (SP) species, respectively, were produced according to the bandsharing values

\begin{tabular}{cccc}
\hline \hline Species & SC & HR & SP \\
\hline SC & $0.661 \pm 0.081^{\mathrm{d}}$ & $0.459 \pm 0.072^{\mathrm{a}}$ & $0.508 \pm 0.073^{\mathrm{b}}$ \\
HR & - & $0.555 \pm 0.074^{\mathrm{c}}$ & $0.495 \pm 0.044^{\mathrm{b}}$ \\
SP & - & - & $0.587 \pm 0.069^{\mathrm{c}}$ \\
\hline
\end{tabular}

SC: Styela clava, HR: Halocynthia roretzi, SP: Styela plicata

${ }^{\mathrm{a} d}$ : Values with different superscript are significantly different, $P<0.05$

Each value is a result of three different experiments.

exhibited higher bandsharing values than did individuals from HR species $(0.555 \pm 0.074)(P<0.05)$, as illustrated in Table 4. The dendrogram resulted from trustworthy seven oligonucleotides primers, indicating three genetic groups composed of cluster I (CLAVA 01, 02, 03, 04, 05, 06 and 07), cluster II (RORETZI 08, 09, 10, 11, 12, 13 and 14) and cluster III (PLICATA 15, 16, 17, 18, 19, 20 and 21), as shown in Fig. 1. The genetic distance among the three ascidian species ranged from 0.071 to 0.599 . In three ascidian species, the longest genetic distance (0.599) exhibiting significant molecular difference was also between individual no. 02 within SC species and individual no. 14 within HR species. The shortest genetic distance (0.071) exhibiting significant molecular difference was also between individual no. 20 and no. 21 within the SP species.

DNA fragments identified in this study may be useful as a DNA marker. This cluster analysis revealed the patterns similar to those posited by Cagigas et al. (1999) and Yoon $\&$ Kim (2004). By means of the cluster analysis of genetic similarity values obtained from genetic data, the genetic distance ranged from 0.091 to 0.316 within and among four natural Spanish populations of brown trout (Salmo trutta) (Cagigas et al., 1999). The values of the pairwise comparisons of unbiased genetic distance between the populations of the Indian major carp (Catla catla) from the combined data for the four primers, ranged from 0.025 to 0.052 (Islam et al., 2005). They reported that the Padma

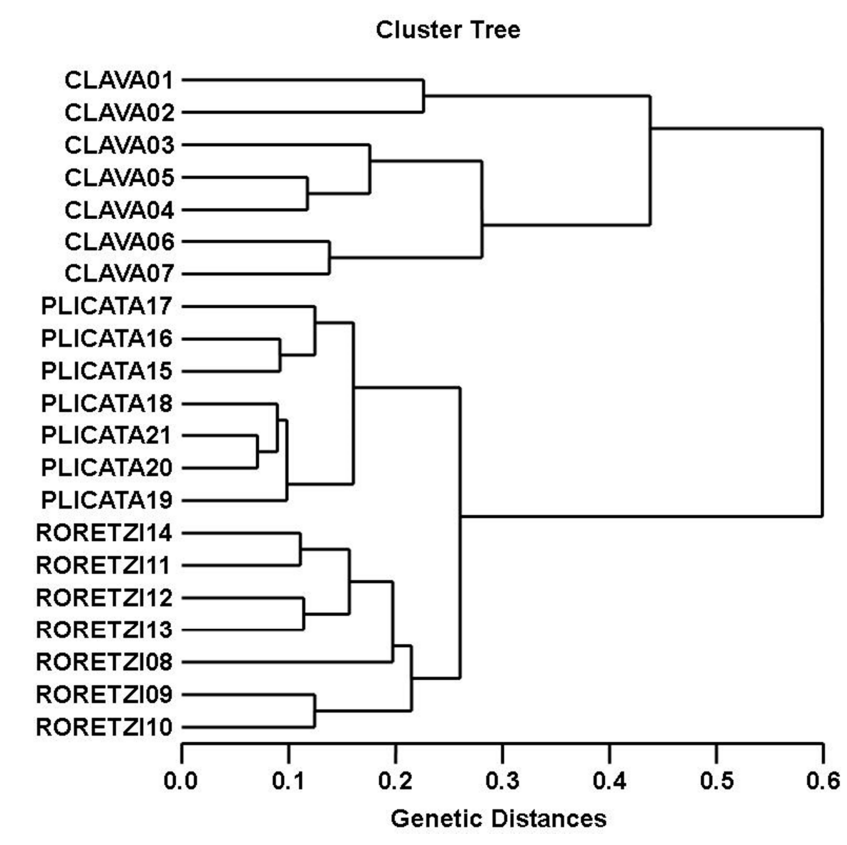

Fig. 1. Hierarchical dendrogram of Euclidian genetic distances, accomplished from three ascidian species. The related construction among different individuals from Styela clava (CLAVA 01 CLAVA 07), Halocynthia roretzi (RORETZI 08 RORETZI 14) and Styela plicata (PLICATA 15 PLICATA 21) species, respectively, was created in line with the bandsharing values and similarity matrix.

and the Jamuna populations were separated from each other with the lowest genetic distance $(\mathrm{D}=0.025)$. The genetic distance between the Indian Ocean lobster and the Korean slipper lobster species ranged between 0.040 and 0.612 (Park et al., 2005). They suggested that this genetic 
technique could be used to discriminate between different river populations of major carp. Consequently, PCR analysis generated on the genetic data displayed that Styela clava (SC) species was widely divided from Halocynthia roretzi (HR) species. Oppositely, individuals of Halocynthia roretzi species were properly closely related to those of Styela plicata species, as revealed in the hierarchical dendrogram of genetic distances. As stated above, the prospective of this analysis to identify pinpointing markers for the identification of the other vertebrates and/or invertebrates species has also been verified (Partis \& Wells, 1996; Tassanakajon et al., 1998; Mamuris et al., 1999; McCormack et al., 2000; Diaz-Jaimes \& Uribe-Alcocer, 2003; Song \& Yoon, 2013). Generally speaking, this PCR analysis been applied to determine specific markers unambiguous to species, genus and geographical population, as well as genetic polymorphism in diverse species of living being (McCormack et al., 2000; Yoon \& Kim, 2004; Park et al., 2005; Oh \& Yoon, 2014). Preferentially, the habitat classification of the class Ascidiacea is based on morphological variations in tunic shape, tunic color, length and weight as well PCR analysis. In future, further more research is necessary for more profound population/species identification in ascidians.

\section{ACKNOWLEDGEMENTS}

The author thanks also to anonymous referees who assisted with detailed and profound correction. Particular thanks go to J-H Jeon and my laboratory colleagues for their support in sample collection and their help with the procedure of PCR technique and statistical analysis.

\section{REFERENCES}

Adams RP (2000) Systematics of the one seeded Juniperus of the eastern hemisphere based on leaf essential oils and random amplified polymorphic DNAs (RAPDs).
Biochem Syst Ecol 28:529-543.

Bartish IV, Garkava LP, Rumpunen K, Nybom H (2000) Phylogenetic relationships and differentiation among and within populations of Chaenomeles Lindl. (Rosaceae) estimated with RAPDs and isozymes. Theor Appl Genet 101:554-563.

Cagigas ME, Vazquez E, Blanco G, Sánchez JA (1999) Combined assessment of genetic variability in populations of brown trout (Salmo trutta L.) based on allozymes, microsatellites, and RAPD markers. Mar Biotechnol 1: 286-296.

Diaz-Jaimes P, Uribe-Alcocer M (2003) Allozyme and RAPD variation in the eastern Pacific yellowfin tuna (Thunnus albacares). Fish Bull 101:769-777.

Guo BZ, Li RG, Widstrom NW, Lynch RE, Cleveland TE (2001) Genetic variation within maize population GTMAS: gk and the relationship with resistance to Aspergillus flavus and aflatoxin production. Theor Appl Genet 103: 533-539.

Huh YB, Choi DL (2008) The studies on stability of cultured sea squirt aquaculture fisheries. Report of NIFS. p311.

Islam MS, Ahmed ASI, Azam MS, Alam MS (2005) Genetic analysis of three river populations of Catla catla (HAMILTON) using randomly amplified polymorphic DNAs markers. Asian-Aust J Anim Sci 18:453-457.

Iyengar A, Piyapattanakorn S, Dtone DM, Heipel DA, Howell BR, Baynes SM, Maclean N (2000) Identification of microsatellite repeats in turbot (Scophthalmus maximus) and dover sole (Solea solea) using a RAPD-based technique: Characterization of microsatellite markers in dover sole. Mar Biotechnol 2:49-56.

Jeffreys AJ, Morton DB (1987) DNA fingerprints of dogs and cats. Anim Genet 18:1-15.

Lee JH (2011) Development of culture technical for solitary ascidian, Halocynthia aurantium. Report of NIFS. p47.

Mamuris Z, Stamatis C, Bani M, Triantaphyllidis C (1999) Taxonomic relationships between four species of the 
Mullidae family revealed by three genetic methods: allozymes, random amplified polymorphic DNA and mitochondrial DNA. J Fish Biol 55:572-587.

McCormack GC, Powell R, Keegan B (2000) Comparative analysis of two populations of the brittle star Amphiura filiformis (Echinodermata: Ophiuroidae) with different life history strategies using RAPD markers. Mar Biotechnol 2: 100-106.

Nebauer SG, del Castillo-Agudo L, Segura J (2000) An assessment of genetic relationships within the genus Digitalis based on PCR-generated RAPD markers. Theor Appl Genet 100:1209-1216.

Nicolosi E, Deng ZN, Gentile A, La Malfa S, Continella G, Tribulato E (2000) Citrus phylogeny and genetic origin of important species as investigated by molecular markers. Theor Appl Genet 100:1155-1166.

Oh H, Yoon JM (2014) Genetic distances of three mollusk species investigated by PCR analysis. Dev Reprod 18 (1):43-49.

Park SY, Park JS and Yoon JM (2005) Genetic differences and variations in slipper lobster (Ibacus ciliatus) and deep sea lobster (Puerulus sewelli) determined by RAPD analysis. Korean J Genet 25:307-317.
Partis L, Wells RJ (1996) Identification of fish species using random amplified polymorphic DNA (RAPD). Mol Cell Probes 10:435-441.

Shin YK, Choi NJ, Huh YB, Han HK, Park JH, Kim Y (2007) Survival and Physiological Responses of the Tunicate Halocynthia roretzi to Salinity Changes. J Aqua 20:226-231.

Song YJ, Yoon JM (2013) Genetic differences of three Pollicipes mitella populations identified by PCR analysis. Dev Reprod 17:199-205.

Tassanakajon A, Pongsomboon S, Jarayabhand P, Klinbunga S, Boonsaeng V (1998) Genetic structure in wild populations of black tiger shrimp (Penaeus monodon) using randomly amplified polymorphic DNA analysis. J Mar Biotechnol 6: 249-254.

Yoke-Kqueen C, Radu S (2006) Random amplified polymorphic DNA analysis of genetically modified organisms. J Biotechnol 127:161-166.

Yoon JM, Kim JY (2004) Genetic differences within and between populations of Korean catfish (S. asotus) and bullhead (P. fulvidraco) analysed by RAPD-PCR. AsianAust J Anim Sci 17:1053-1061. 